\title{
Optimization of CNC Milling Parameters for Complex 3D Surfaces of SIMOLD 2083 Alloy Mold Core Utilizing Multiobjective Water Cycle Algorithm
}

\author{
Chi Thien Tran, ${ }^{1}$ Minh Phung Dang, ${ }^{1}$ Hieu Giang Le, ${ }^{1}$ Ngoc Le Chau, ${ }^{2}$ \\ and Thanh-Phong Dao $\mathbb{1}^{3,4}$ \\ ${ }^{1}$ Faculty of Mechanical Engineering, Ho Chi Minh City University of Technology and Education, Ho Chi Minh City, Vietnam \\ ${ }^{2}$ Faculty of Mechanical Engineering, Industrial University of Ho Chi Minh City, Ho Chi Minh City, Vietnam \\ ${ }^{3}$ Division of Computational Mechatronics, Institute for Computational Science, Ton Duc Thang University, \\ Ho Chi Minh City, Vietnam \\ ${ }^{4}$ Faculty of Electrical and Electronics Engineering, Ton Duc Thang University, Ho Chi Minh City, Vietnam
}

Correspondence should be addressed to Thanh-Phong Dao; daothanhphong@tdtu.edu.vn

Received 31 March 2021; Accepted 4 May 2021; Published 11 May 2021

Academic Editor: Dr. Dilbag Singh

Copyright $\odot 2021$ Chi Thien Tran et al. This is an open access article distributed under the Creative Commons Attribution License, which permits unrestricted use, distribution, and reproduction in any medium, provided the original work is properly cited.

In this article, an effective multiobjective optimization approach is exploited to search for the best milling parameters for CNC for complex 3d surfaces of SIMOLD 2083 alloy mold core. To improve the quality responses, the cutting factors are optimized by a combination of Taguchi method (TM), response surface method (RSM), and multiobjective water cycle algorithm (MWCA). Firstly, the design for initial series experiments of the cutting factors was generated via the TM. Thereafter, the regression models between the cutting factors and the surface roughness of the machined workpiece surface as well as milling time are formed via applying the RSM. Moreover, analysis of variance and sensitivity analysis are also executed to define the influences and crucial contributions of cutting parameters on the surface roughness and milling time. The results of analysis of variance showed that the factors which have main effects on surface roughness were spindle speed (42.42\%), feed rate (29.40\%), and cutting depth (6.59\%), respectively. Meanwhile, the feed rate with the influence of $92.6 \%$ was the most significant factor in controlling the milling time. Ultimately, based on mathematical models, the MWCA is performed to define the optimal factors. The optimal results indicated that the optimized surface roughness was about $0.260 \mu \mathrm{m}$ and the milling time was roughly $1012.767(s)$. In addition, the errors between forecasted results and experimental verifications for the surface roughness and milling time are 2.04\% and 5.39\%, respectively. Therefore, the results of experimental verifications are suitable with the forecasted results from the proposed optimization method. These results depicted that the proposed integration approach can define effectively the optimal cutting factors for $\mathrm{CNC}$ milling and expand to apply for complex multiobjective optimization problems.

\section{Introduction}

Currently, SIMOLD 2083 alloy is well known as material with excellent mechanical characteristics such as extreme erosion resistance and self-hardening in high temperature and friction, so it is extensively utilized in the molding industries for food field. For more specifics, this material can be hardened by itself in the operating process when the working environment has friction and high temperature, so it is very appropriate for injection molding. Another benefit of SIMOLD 2083 alloy is of the stainless steel group; it is also suitable for making the molding cavities and cores for plastic products used in the food area. Meanwhile, the fabrication process of SIMOLD 2083 alloy with complex 3D surfaces meets several struggles for achieving small surface roughness and high productivity because of detrimental machining conditions. Therefore, in order to obtain the beneficial surface quality as well as ensure machining productivity, the cutting parameters should be chosen in a suitable range and be optimized to gain the optimal milling conditions. There 
are various parameters such as the cutting parameters and chemical composition of workpiece and tool affecting the quality characteristics of the milled components. In addition, surface roughness is one of the most characteristics of the milling parts. In this research, so as to guarantee the quality and productivity of machining part with the complex milling surfaces, the surface roughness and milling time were considered. Consequently, so as to achieve better surface finish of a milled product and ensure the productivity, the cutting parameters were regarded for multiobjective optimization problem.

In general, the surface roughness and milling time are the significant characteristics. However, two characteristics are wriggled together. Therefore, in order to equalize and obtain the requirements of a small roughness surface and low milling time, concurrently, the hybrid approach is proposed for performing the multiobjective optimization problem. In addition, the key cutting factors were optimized for gaining the above-mentioned requirements.

Generally, the Taguchi method (TM) is extensively utilized in optimal analysis engineering for creating the minimized initial data [1]. For examples, Gopalsamy et al. [2] utilized the TM to find the optimized cutting factors of hardened steel. It was monitored that the cutting velocity is the greatest effect factor on surface roughness as well as tool life. Gürcan Samtas [3] utilized the TM for optimization of cutting factors for the machining surfaces of AA5083-H111. Moreover, in previous studies, several population-based algorithms were advanced. For instance, the main parameters of power system were identified by the genetic algorithm (GA) [4]. Soori et al. [5] utilized the GA to define optimized machining parameters based on a virtual machining system. Gupta et al. [6] utilized evolutionary techniques for optimizing machining parameters of titanium alloy. Basu et al. applied cuckoo search algorithm for dispatch trouble [7]. Compared to aforementioned methods, in order to improve convergence speed with less initial factors, several efficient optimal methods [8-12] were proposed. In addition, as another integration way to conduct single optimal problem, for instance, Kadirgama et al. [13] proposed hybrid approach RSM as well as radian basis function network for optimizing the cutting factors in order to minimize the surface roughness of aluminum alloy, for finding the most noteworthy factors on carbon nanotubes by the adaptive neurofuzzy inference system (ANFIS) approach [14]. Moreover, several other effective methods for prediction are such as a saliency detection method [15], outlier recognition in neutrosophic sets [16], color image encryption [17], optimizing the working parameters of a PVT system [18], and complex neutrosophic set [19]. Especially, in order to conduct multicriteria search, a lot of multiobjective optimization techniques have been applied for many areas. For instance, multiobjective evolutionary optimization is for image encryption [20], for fabrication biocompatible [21], for human manner recognition [22], for microarray cancer data categorization [23], for visibility enhancement and mass division of mammogram figures [24], for hydraulic machinery in engine velocity decrease [25], and for multi-image fusion [26]. Furthermore, there have been combination of different techniques; e.g., the TM was combined with response surface method (RSM) and genetic algorithm (GA) [27], GA-artificial neural network (ANN) and PSO-ANN [28], the TM-fuzzy according to moth-flame optimization [29], particle swarm optimization (PSO) [30] and GA [31], RSM-PSO [32] and gravitational search algorithm-GA [33, 34], Grey, TM, RSM and entropy measurement [35], fuzzy logic-ANFIS-based lightning attachment procedure optimization [36], TM-RSM, improved ANFIS, and TLBO [37]. For more specifics, Shrivastava and Singh [38] developed a combined method of RSM and multiobjective genetic algorithm for evaluation of enduring cutting region in CNC turning. Recently, multicriteria water cycle algorithm (MWCA) was considered as an effective optimizer for many sectors [39-42]. However, an integration approach of TM, RSM, and MWCA for optimizing the cutting parameters of mold core utilizing SIMOLD 2083 alloy with complex milled $3 \mathrm{D}$ surfaces in the small ice cube mold has not been researched yet.

This paper proposes an effectual optimization approach for the cutting factors of mold core with complex 3D surfaces applied for the small ice cube mold. So as to resolve the optimization, a combination method of the TM, RSM, and MWCA is developed.

\section{Methodology}

2.1. Formulation of Optimization Problem. In this research, the milled component with complex milling surfaces should fulfill the following requirements: (i) the surface roughness $\left(y_{1}\right)$ should be as small as possible to assure the quality of the milling inclined surface and (ii) the small milling time $\left(y_{2}\right)$ to enhance the machining productivity. A combination method of the TM, the RSM, and the MWCA is grown for balance among them as well as advance of the superiority responses. The optimal issue for the milled component is expressed in the following form.

Find the design variables: $x=[S, F, t]$.

Minimize the $y_{1}(S, F, t)$,

$$
y_{1}(S, F, t)
$$

Minimize the $y_{2}(S, F, t)$,

$$
y_{2}(S, F, t)
$$

Subject to constraints:

$$
\left\{\begin{array}{l}
3179 \mathrm{rpm} \leq S \leq 6309 \mathrm{rpm} \\
636 \mathrm{~mm} / \mathrm{min} \leq F \leq 1206 \mathrm{~mm} / \mathrm{min} \\
0.03 \mathrm{~mm} \leq t \leq 0.3 \mathrm{~mm}
\end{array}\right.
$$

where $y_{1}$ and $y_{2}$ are the quality responses. $F, S, t$ are spindle velocity, feed rate, and cutting depth, respectively.

To ensure the complex 3D surface machining quality and milling productivity, the surface roughness and the machining time should be selected as small as possible.

Based on the technical requirements and milling productivity, the value of surface roughness was proposed for 
being lower $0.4(\mu \mathrm{m})$ and the milling time was also lower $1060(s)$.

Equation (3) illustrated the constrained range of the input variables. The bounds for the cutting factors were proposed based on professional knowledge, machining capacity of the CNC vertical milling machine, workpiece material, namely, SIMOLD 2083 (DIN-X40Cr14) with hardening to achieve 48-50HRC with chemical composition, as illustrated in Table 1 and tool material (ball mill, code: CEB20300A, $R=3, L_{1}=12, L=50, D=6, F=2$ with coated TiAlN, HRC $=55 \mathrm{RC}$, twist angle $=30$ ), as illustrated in Figure 1.

2.2. Hybrid Approach. An integration approach is developed for investigating the impacts of the cutting factors for the milled component on multicriteria output characteristics and detecting the optimized factors for the proposed milled component.

Initially, the TM was exploited for identifying an orthogonal array to form an initial experiment plan. Furthermore, analysis of variance (ANOVA) was exploited to identify the important ratio impact of each cutting factor on the quality characteristics.

Subsequently, the relationships between the cutting factors and the quality characteristics are established by the RSM. A full quadratic formulation is a fitting type for the milled component as the following equation:

$$
Y_{j}=\beta_{0}+\sum_{i=1}^{n} \beta_{i} x_{i}+\sum_{i=1}^{n} \beta_{i j} x_{i}^{2}+\sum_{i=1}^{n-1} \sum_{j=i+1}^{n} \beta_{i j} x_{i} x_{j}+\varepsilon_{i},
$$

where $\beta_{i}(i=0,1,2, \ldots, \mathrm{n})$ are unknown regression coefficients, $\beta_{i j}(i<j)$ are relation coefficients, $x_{1}, x_{2}, \ldots, x_{n}$ is a set of $n$ forecasters trusted to be interrelated to a response variable $Y_{j}$, and $\varepsilon$ is a haphazard error.

\subsubsection{Multiobjective Water Cycle Algorithm. According to} the established regression equations, the optimal procedure was performed by MWCA algorithm. The MWCA has been extensively exploited [43-46], but it has not been applied for optimization of the cutting parameters of milled mold core component with complex milling surfaces. The action rule of this algorithm is inspired from the drainage of rivers and streams unto the sea and originated via the supervision of water cycle procedure. For specifics, water travels downwards for generating streams and rivers, beginning from high points on the hills, later on, moving to the lakes and seas. Streams and rivers gather water from rain and other streams. The water of rivers and lakes will evaporate. Later on, clouds are created when the evaporated water is moved in the atmosphere. These clouds squeeze in the colder atmosphere and discharge the water in order to find rain, generating new streams and rivers. Moving to more detailed analysis of this algorithm, the MWCA exploits the perception of travelling implicitly from streams to the rivers as well as from rivers to the sea (best solution). In this algorithm, rivers (many greatest chosen resolutions omitting the
TABLE 1: The composition of workpiece material.

\begin{tabular}{lccccc}
\hline $\mathrm{C}$ & $\mathrm{Si}$ & $\mathrm{Mn}$ & $\mathrm{Cr}$ & $P$ & $\mathrm{~S}$ \\
\hline \multirow{2}{*}{$0.36-0.42$} & Max. & Max. & \multirow{2}{*}{$12.50-14.50$} & Max. & Max. \\
& 1.0 & 1.0 & & 0.025 & 0.005 \\
\hline
\end{tabular}

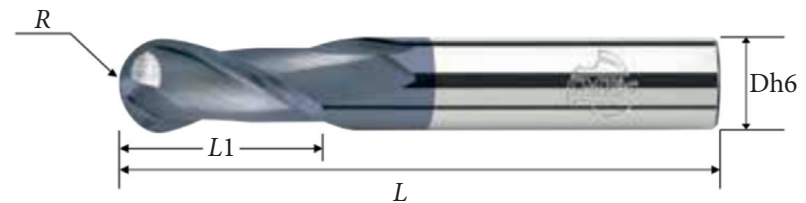

FIgURe 1: Basic geometric dimensions of ball mill.

greatest one (sea)) operate as guiding creatures for targeting other creatures in the inhabitants (streams) on the way to greater locations. In addition, rivers also travel on the way to the sea and they are not regarded as fixed creatures in the inhabitant. Actually, the procedure includes (i) the streams travel to the river and (ii) rivers travel to the sea leading to implicit travels near the best solution (sea) via the water cycle. The more details can be read in refs. [39-42].

Ultimately, according to the regression equations, the MWCA was utilized to seek the optimization parameters. The MWCA was utilized for solving multicriteria optimization issue due to its great power for finding optimal resolutions close to the universal finest proficiently. The programing of MWCA algorithm was conducted via MATLAB 2017. Flowchart and plan of fabricating factors optimization via hybrid approach are suggested, as in Figure 2.

\section{Experimental Results and Discussion}

3.1. Orthogonal Array Experiment. Every factor could be segregated for three grades based on professional knowledge and machining experiences, as indicated in Table 2. According to the TM, the $L_{9}$ orthogonal array was adopted for forming the initial experiment strategy.

3.2. Experimental Process and Mathematical Model. First of all, the 3D model of the small ice cube mold was designed by Creo software, as illustrated in Figure 3. In addition, for enhancing the milled surfaces property of the mold core and productivity, private specimens of the core component were fabricated based on the TM to generate initial data for enhancing the aforementioned responses. Figure 4 depicted the yellow milled surfaces of the mold core with square of $420.101 \mathrm{~mm}^{2}$.

Secondly, the nine fabricated experimental models were fabricated according to proposed the number of experiments, as depicted in Figure 5. Later on, the surface roughness $\left(y_{1}\right)$ was assessed by a Mitutoyo SJ-210 surface roughness tester (Japan), as illustrated in Figure 6. Besides, in order to transfer inclined surface into straight surface for measuring surface roughness, the mounting fixture was designed and fabricated for fixing the milled component as well as conveying measuring surfaces with the average of 


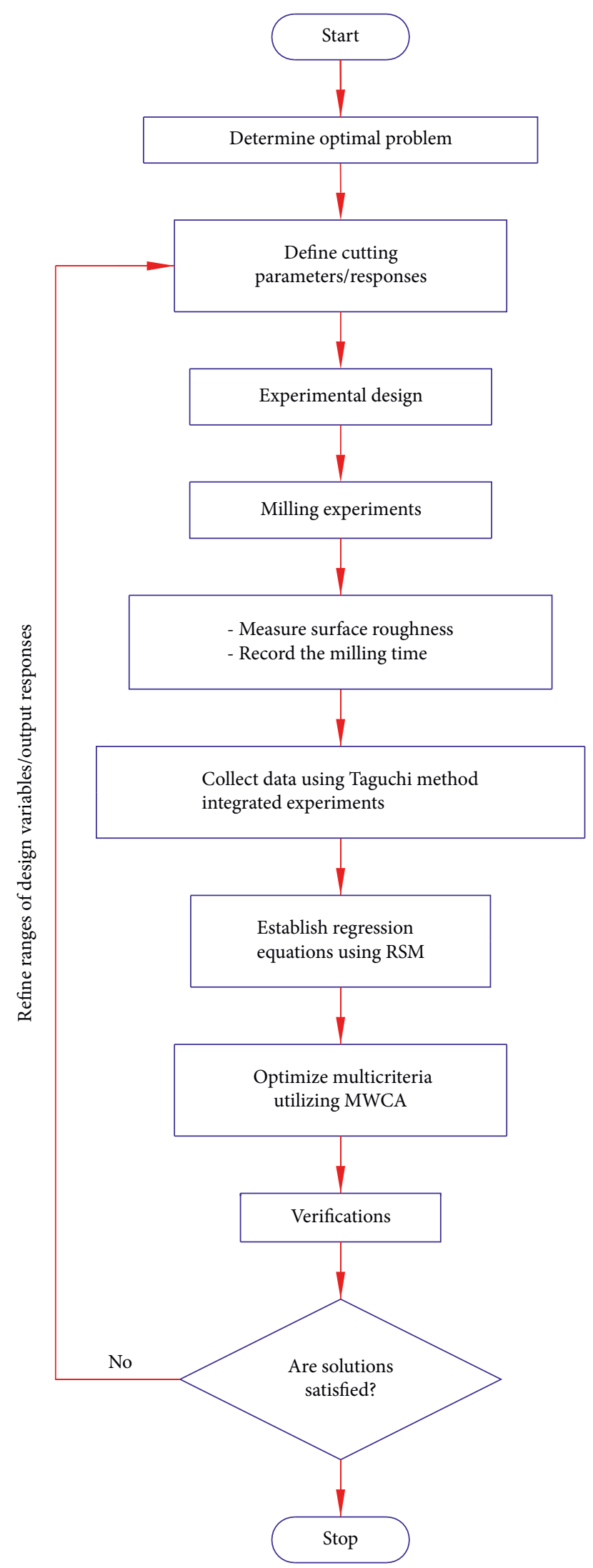

FIGURE 2: Flowchart and plan of fabricating factors optimization via hybrid approach. three different measurements, in addition to the machining time $\left(y_{2}\right)$ and that recorded by CNC machine, respectively. Therefore, the experimental results are shown in Table 3.

Thirdly, according to the experiment outcomes in Table 2, the regression equations for two responses were established as follows:

The mathematical models could be gained in form of

$$
\begin{aligned}
y_{1}= & 2.969-0.000379^{*} S-0.002910^{*} F-4.691 t \\
& +0.000002 F^{*} F+8.386 t^{*} t+0.000313^{*} S^{*} t, \\
y_{2}= & 1315-0.001090^{*} S-0.4990^{*} F+0.7928^{*} t \\
& +0.000210 F^{*} F+19.05 t^{*} t-0.001520^{*} S^{*} t .
\end{aligned}
$$

Tables 4 and 5 demonstrate the ANOVA results of the surface roughness and milling time. The evaluation was executed with 5\% significance level and 95\% insurance level.

As described in Table 4, the influence degree on the surface roughness $y_{1}$ of $S$ was greatest, at $42.42 \%$, while the effect figure for $F$ and interaction $t$ and $t$ was substantially higher, at $29.40 \%$ and $13.22 \%$, correspondingly. Meanwhile, the rate of $t$ and interaction $F$ and $F$ was relatively lower, at $6.59 \%$ and $3.76 \%$, respectively. In addition, the influence rate on the surface roughness $y_{1}$ of interaction $S$ and $S$, interaction $S$ and $t$, and interaction $S$ and $F$ was slightly lower, at $1.95 \%, 1.56 \%$, and $1.12 \%$. Therefore, so as to reduce the value of $y_{1}$, factors $S$ and $F$ should be significantly considered.

As demonstrated in Table 5, the influence percentage of $F$ on $y_{2}$ was the highest, at $92.60 \%$, while the influence number for interaction $F$ as well as $F$ was small, at $7.39 \%$ respectively. In contrast, other factors did not significantly affect $y_{2}$. Thus, so as to decline the worth of $y_{2}$, the only factor $F$ should be especially considered. Furthermore, the influence rate of error for $y_{1}$ as well as $y_{2}$ was $0 \%$.

3.3. Sensitivity Analysis. Statistic method was executed for identifying the influence level of input cutting factors on the output characteristics. In the range $(3179,6309)$, parameter $S$ affected $y_{1}$ in reducing gradually, as represented in Figure 7. In addition, parameter $F$ illustrated that in the range (636, 831 ), it influenced a slight increase to $y_{1}$, but, in the range $(831,1206)$, it affected a gradual increase to $y_{1}$. Furthermore, there was a fluctuation influence of parameter $t$ to $y_{1}$. Moving to a more detailed analysis, in the range $(0.03,0.165)$, parameter $t$ caused $y_{1}$ to degrade slightly, but, in the range $(0.03,0.165)$, it influenced a gradual rise to $y_{1}$.

On the other hand, as shown in Figure 8, there was only a decrease influence of parameter $F$ to $y_{2}$. For specifics, parameter $F$ illustrated that in the range $(636,1026)$, it influenced a sharp decrease to $y_{2}$.

In summary, whole effects of input variables on quality characteristics were exhibited, as in Figure 9. The figure described a surge and drop variation in each factor. According to the outcomes, the key elements could be varied to obtain the suitable cutting parameters for fabricating the milled component. 
TABLE 2: Input cutting factors and their grades.

\begin{tabular}{lccccc}
\hline Factors & Range & Lower grade & Average grade & Upper grade & Unit \\
\hline$S$ & $3179-6309$ & 3179 & 4609 & 6309 & $\mathrm{rpm}$ \\
$F$ & $636-1206$ & 636 & 831 & 1206 & $(\mathrm{~mm} / \mathrm{min})$ \\
$t$ & $0.03-0.3$ & 0.03 & 0.165 & 0.3 & $(\mathrm{~mm})$ \\
\hline
\end{tabular}

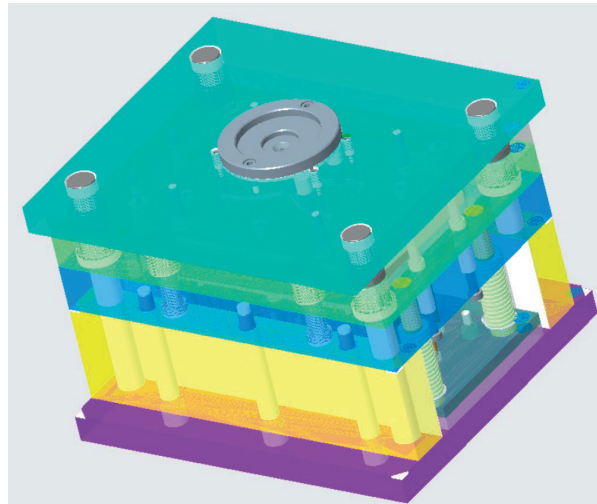

(a)

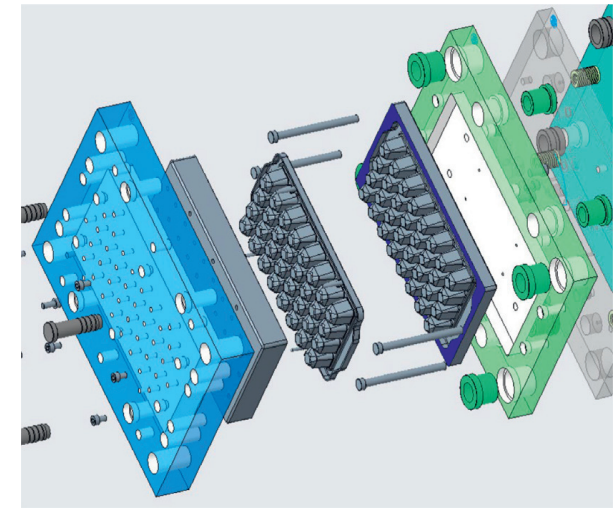

(b)

Figure 3: A 3D design drawing of the small ice cube mold of (a) assembly drawing and (b) exploded drawing.

3.4. Optimal Results. Firstly, the number of numerical experiments was generated applying the TM. Based on initial data which were established by the TM, nine models were fabricated, measured as well as recorded so as to gain the values of output responses including surface roughness and milling time. In addition, according to these data between input variables and two output responses, the RSM was employed for establishing the regression equations for the surface roughness and the milling time. Later on, the multiobjective optimization problem was conducted via the MWCA. The MWCA algorithm was accomplished via MATLAB 2017b. The initial factors of MWCA are given in Table 6.

The optimized results were discovered at $S=4989.13671955611 \mathrm{rpm}, F=1182.37762276541 \mathrm{~mm} / \mathrm{min}$, $t=0.0674096477686595 \mathrm{~mm}, \quad y_{1}=0.260586713 \mu \mathrm{m}$, and $y_{2}=1012.767751(s)$. The results revealed that the optimal surface roughness and milling time are satisfying the technical requirements as well as milling productivity and are suitable for the complex surfaces milling process. Based on the optimized parameters, the mold core with material, namely, SIMOLD 2083 (DIN-X40Cr14), was fabricated with 32 models for integration into the small ice cube mold, as illustrated in Figure 10. Later on, the small ice cube mold was installed into plastic injection molding machine, as shown in Figure 11, for producing enormous and identical quantities of plastic trays, as illustrated in Figure 12.

3.5. Validation. The optimal parameters $(S=4989.137 \mathrm{rpm}$, $F=1182.38 \mathrm{~mm} / \mathrm{min}, t=0.0674 \mathrm{~mm}$ ) were used to fabricate the mold core for experimental certification. The process was

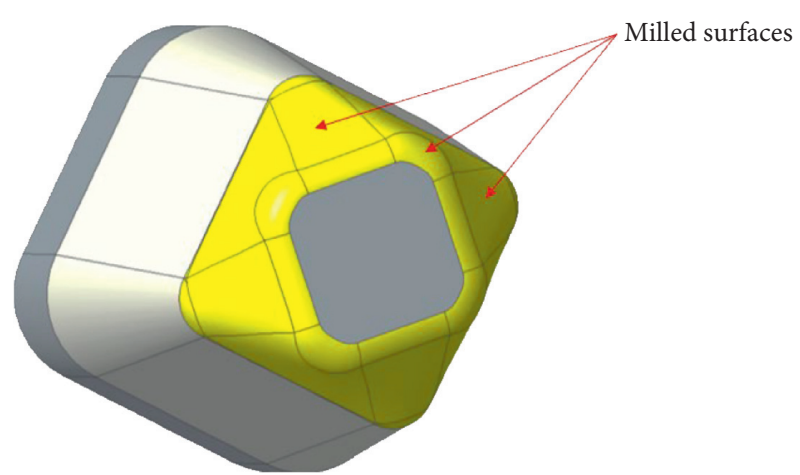

FIGURE 4: The yellow milled surfaces of the mold core with square of $420.101 \mathrm{~mm}^{2}$.

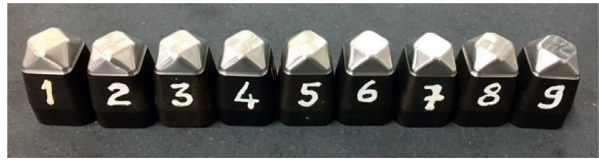

Figure 5: The nine milled experimental models.

accomplished with the same dimension and material of workpiece, the same tool, and the coolant condition. Experimental results based on optimized parameters illustrated that the value of surface roughness and milling time were $0.266 \mu \mathrm{m}$ and 961 (s), as illustrated in Figure 13, respectively. Table 7 demonstrates that the error between forecasted results and experimental certifications for the roughness 


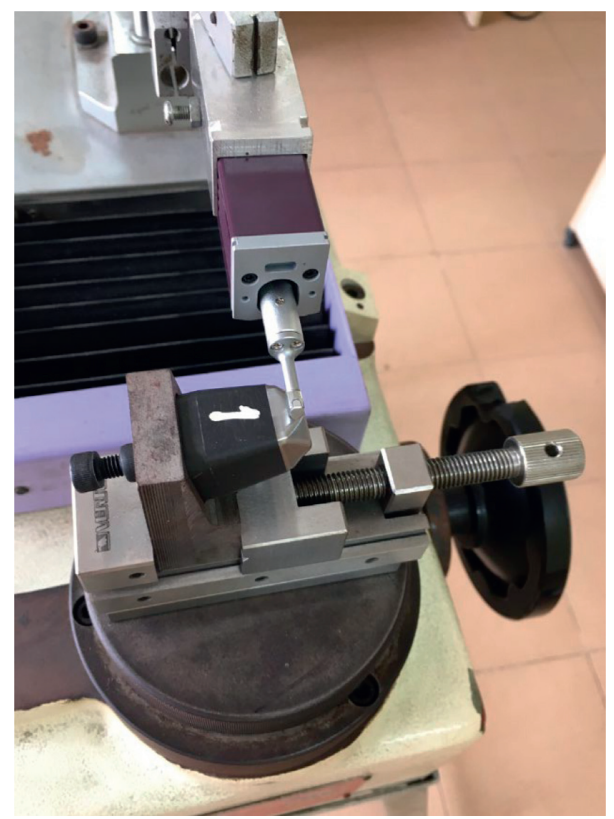

FIGURE 6: Fixture for measuring surface roughness of milled components by surface roughness tester, namely, Mitutoyo SJ-210.

TABLE 3: Experimental results.

\begin{tabular}{|c|c|c|c|c|c|}
\hline No. & $S(\mathrm{rpm})$ & $F(\mathrm{~mm} / \mathrm{min})$ & $t(\mathrm{~mm})$ & $y_{1}(\mu \mathrm{m})$ & $y_{2}(\mathrm{~s})$ \\
\hline 1 & 3179 & 636 & 0.3 & 0.506 & 1081 \\
\hline 2 & 3179 & 831 & 0.165 & 0.416 & 1043 \\
\hline 3 & 3179 & 1206 & 0.03 & 0.96 & 1016 \\
\hline 4 & 4609 & 636 & 0.165 & 0.273 & 1080 \\
\hline 5 & 4609 & 831 & 0.03 & 0.423 & 1043 \\
\hline 6 & 4609 & 1206 & 0.3 & 0.549 & 1016 \\
\hline 7 & 6309 & 636 & 0.03 & 0.308 & 1081 \\
\hline 8 & 6309 & 831 & 0.3 & 0.248 & 1043 \\
\hline 9 & 6309 & 1206 & 0.165 & 0.332 & 1016 \\
\hline
\end{tabular}

TABLE 4: ANOVA analysis for roughness surface.

\begin{tabular}{|c|c|c|c|c|c|c|}
\hline Source & DF & Seq SS & Influence (\%) & Adj SS & Adj MS & $P$ value \\
\hline Model & 8 & 0.381007 & 100.00 & 0.381007 & 0.047626 & Considerable \\
\hline Linear & 3 & 0.298732 & 78.41 & 0.215692 & 0.071897 & Considerable \\
\hline S & 1 & 0.161615 & 42.42 & 0.158897 & 0.158897 & Considerable \\
\hline $\mathrm{F}$ & 1 & 0.112027 & 29.40 & 0.026421 & 0.026421 & Considerable \\
\hline $\mathrm{t}$ & 1 & 0.025091 & 6.59 & 0.012160 & 0.012160 & Considerable \\
\hline Square & 3 & 0.072074 & 18.92 & 0.046166 & 0.015389 & Considerable \\
\hline$S * S$ & 1 & 0.007413 & 1.95 & 0.007413 & 0.007413 & Considerable \\
\hline $\mathrm{F}^{*} \mathrm{~F}$ & 1 & 0.014310 & 3.76 & 0.019953 & 0.019953 & Considerable \\
\hline$t^{*} t$ & 1 & 0.050350 & 13.22 & 0.027617 & 0.027617 & Considerable \\
\hline 2-Way interaction & 2 & 0.010201 & 2.68 & 0.010201 & 0.005100 & Considerable \\
\hline $\mathrm{S} * \mathrm{~F}$ & 1 & 0.004261 & 1.12 & 0.000098 & 0.000098 & Considerable \\
\hline $\mathrm{S}^{*} \mathrm{t}$ & 1 & 0.005940 & 1.56 & 0.005940 & 0.005940 & Considerable \\
\hline Error & 0 & - & - & - & - & \\
\hline Total & 8 & 0.381007 & 100.00 & & & \\
\hline
\end{tabular}


TABLE 5: ANOVA analysis for milling time.

\begin{tabular}{|c|c|c|c|c|c|c|}
\hline Source & DF & Seq SS & Influence (\%) & Adj SS & Adj MS & $P$ value \\
\hline Model & 8 & 6330.22 & 100.00 & 6330.22 & 791.28 & Remarkable \\
\hline Linear & 3 & 5861.88 & 92.60 & 3305.79 & 1101.93 & Remarkable \\
\hline$S$ & 1 & 0.00 & 0.00 & 0.00 & 0.00 & Remarkable \\
\hline$F$ & 1 & 5861.88 & 92.60 & 3142.36 & 3142.36 & Remarkable \\
\hline$t$ & 1 & 0.00 & 0.00 & 0.00 & 0.00 & Remarkable \\
\hline Square & 3 & 468.12 & 7.40 & 281.22 & 93.74 & Remarkable \\
\hline$S^{*} S$ & 1 & 0.22 & 0.00 & 0.22 & 0.22 & Remarkable \\
\hline$F^{*} F$ & 1 & 467.68 & 7.39 & 268.56 & 268.56 & Remarkable \\
\hline$t^{*} \mathrm{t}$ & 1 & 0.22 & 0.00 & 0.14 & 0.14 & Remarkable \\
\hline 2-Way interaction & 2 & 0.22 & 0.00 & 0.22 & 0.11 & Remarkable \\
\hline$S^{*} F$ & 1 & 0.08 & 0.00 & 0.00 & 0.00 & Remarkable \\
\hline$S^{*} t$ & 1 & 0.14 & 0.00 & 0.14 & 0.14 & Remarkable \\
\hline Error & 0 & - & - & - & - & \\
\hline Total & 8 & 6330.22 & 100.00 & & & \\
\hline
\end{tabular}

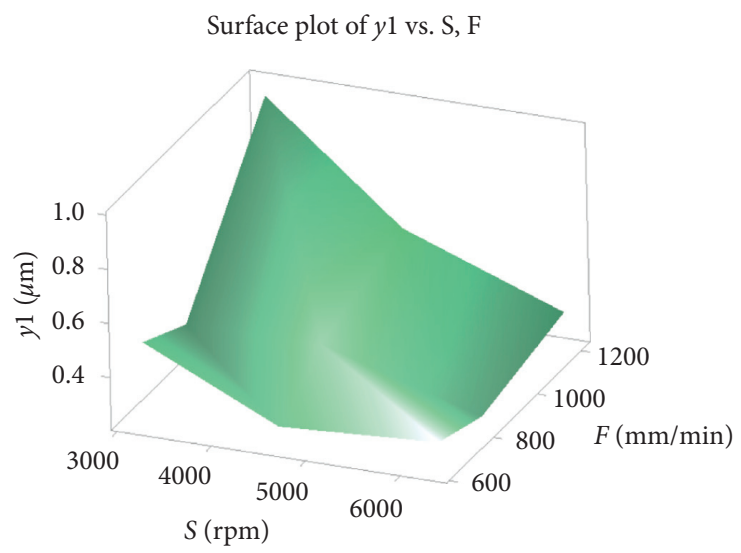

(a)

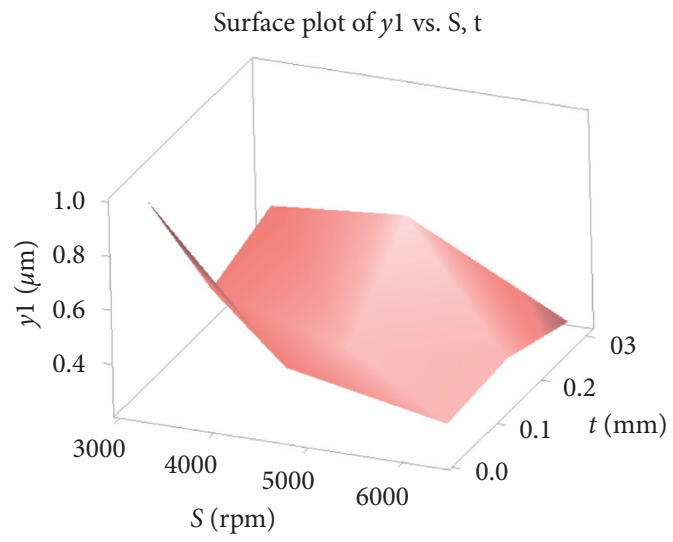

(b)

Figure 7: Influence diagram on surface roughness of (a) $S$ and $F$, (b) $S$ and $t$.

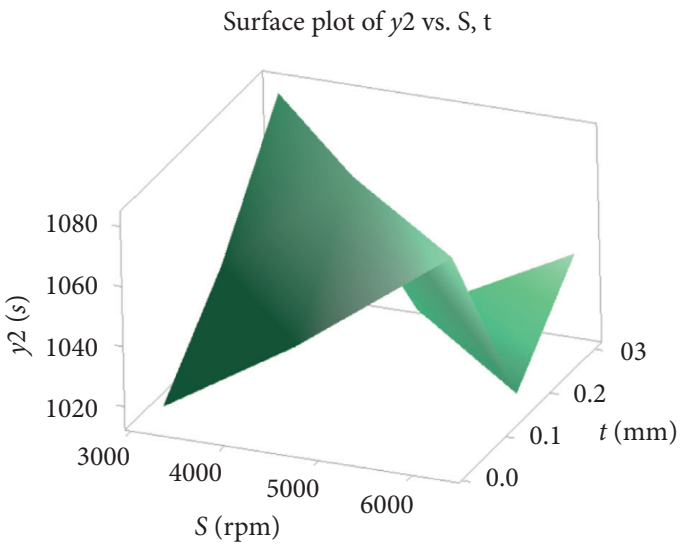

(a)

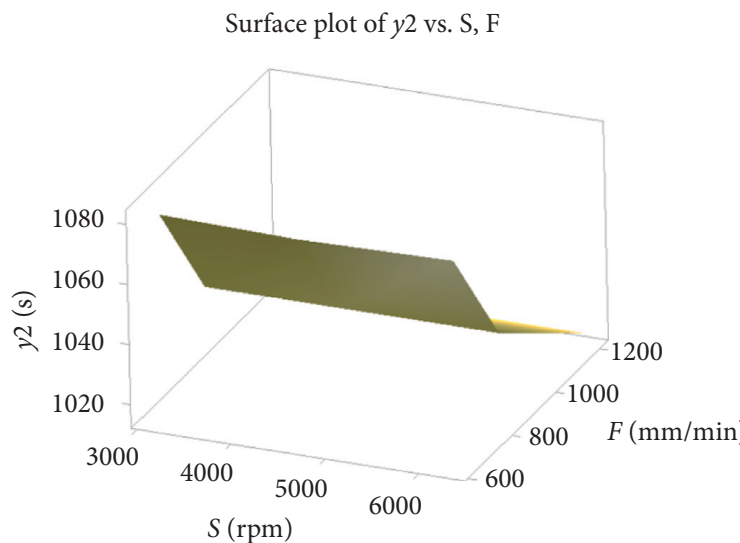

(b)

Figure 8: Influence diagram on milling time of (a) $S$ and $t$, (b) $S$ and $F$. 
Matrix plot of surface roughness and milling time vs. F, S, t

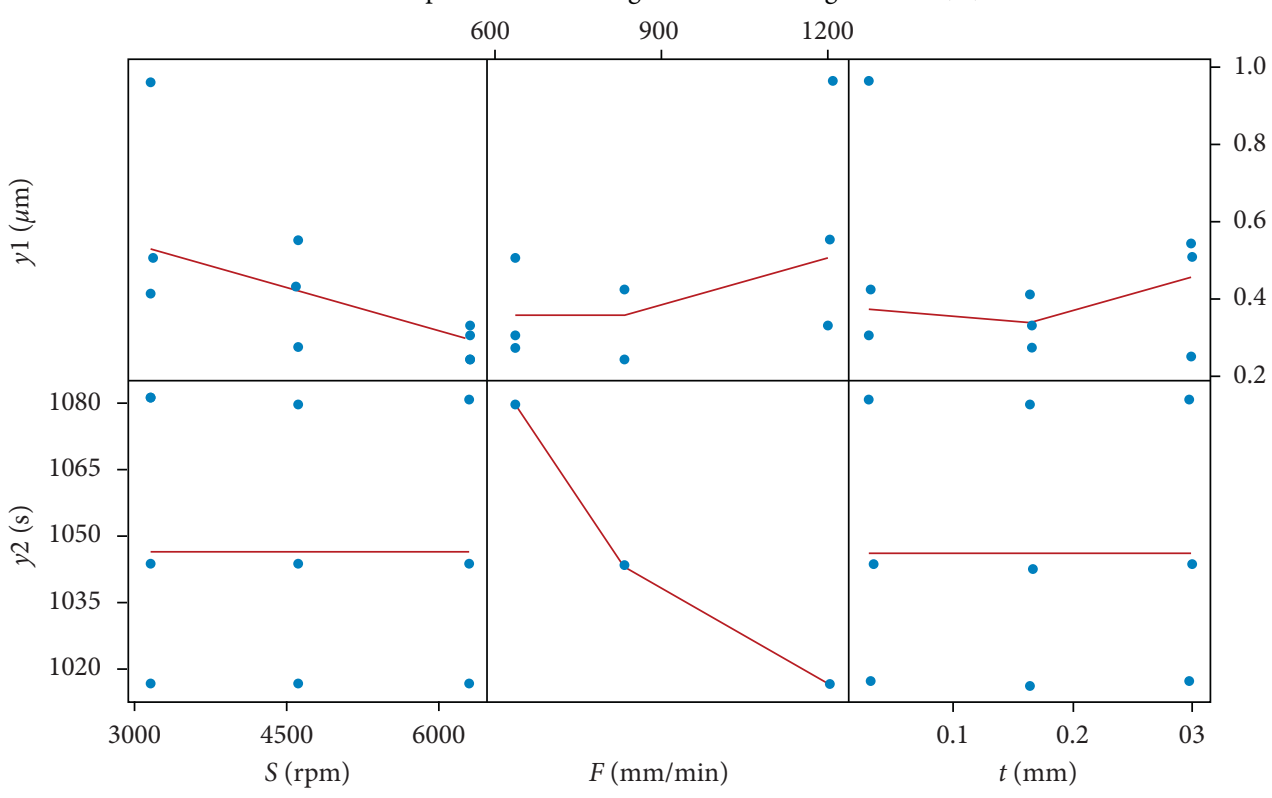

FIGURE 9: Sensitivity diagram of the cutting factors on surface roughness and milling time.

TABLE 6: Utilized initial factors for MWCA.

\begin{tabular}{lc}
\hline Factors & Value \\
\hline Population size & 50 \\
Maximum number of iterations & 100 \\
\hline
\end{tabular}

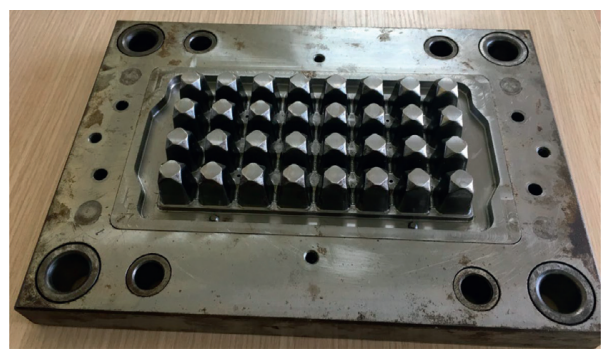

Figure 10: Thirty-two models of the fabricated mold core.
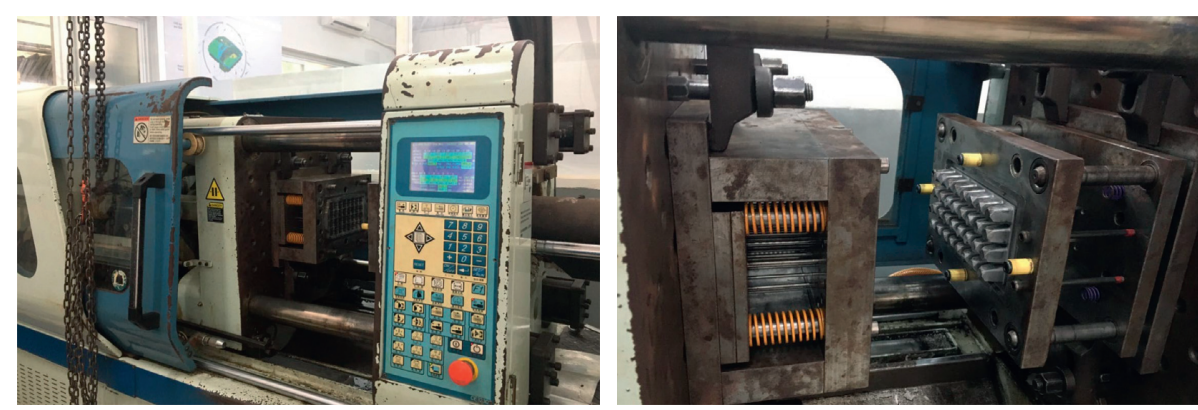

FIGURE 11: Installation of the small ice cube mold on the plastic injection molding machine. 


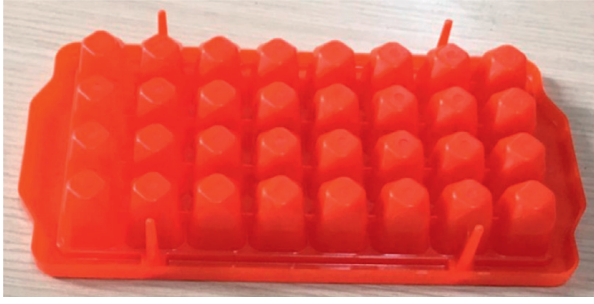

(a)

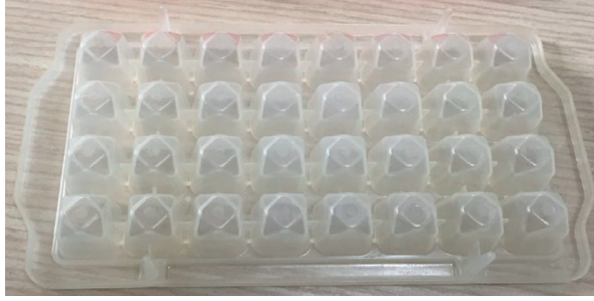

(b)

FIGURE 12: Small plastic ice tray products: (a) red plastic product, (b) white plastic product.

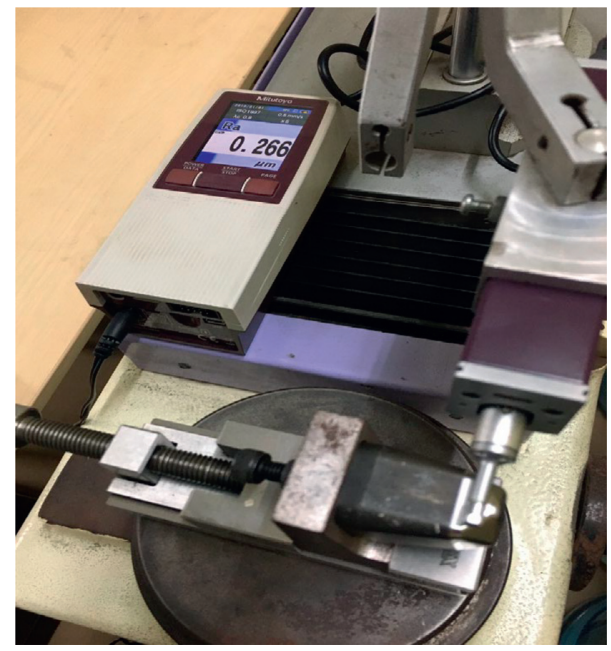

FIGURE 13: Installation for measuring surface roughness based on optimal parameters.

TABLE 7: Errors among predicted results and validated results.

\begin{tabular}{lccc}
\hline Responses & Prediction & Validation & Error $(\%)$ \\
\hline$y_{1}$ (micrometer) & 0.260586713 & 0.266 & 2.04 \\
$y_{2}(\mathrm{~s})$ & 1012.767751 & 961 & 5.39 \\
\hline
\end{tabular}

surface and milling time are $2.04 \%$ and $5.39 \%$, respectively. It is clear that the forecasted results are suitable with verified results.

\section{Conclusions}

This paper offered an effectual combination optimization approach for the mold core component with the complex milling surfaces. The spindle velocity, feed rate, and cutting depth were considered as input design variables. To enhance the surface roughness and milling time, the cutting parameters were optimized by a combination approach of the TM, experimental measurements, RSM, and MWCA.

The sensitivity analysis and ANOVA were implemented for determining the effects and crucial contributions of cutting factors on the surface roughness and milling time. The results of ANOVA analysis showed that the parameters that have significant influences on surface roughness were spindle velocity $(42.42 \%)$, feed rate $(29.40 \%)$, and cutting depth $(6.59 \%)$, respectively. Meanwhile, the only parameter that has the most influence degree on milling time was feed rate $(92.6 \%)$.

The results revealed that the optimized parameters were found at $S$ of $4989.137 \mathrm{rpm}, F$ of $1182.38 \mathrm{~mm} / \mathrm{min}$, and $t$ of $0.0674 \mathrm{~mm}$. Moreover, the results indicated that the surface roughness and milling time were around $0.260586713(\mu \mathrm{m})$ and 1012.767751 (s), respectively.

Moreover, the results illustrated that the errors among forecasted results and experimental validations for the roughness surface and milling time are $2.04 \%$ and $5.39 \%$, congruently. The experimental affirmations were proximate to the forecasted results. Therefore, the predicted results are appropriate with the certifications. According to the aforementioned results, the hybrid method is a powerful method for solving the multiobjective optimization issue for the cutting factors.

Additionally, this study encounters several challenges such as taking lots of time for finding suitable material in fields of injection molding and food as well as designing and manufacturing measuring fixture. Therefore, different 
suitable materials in the areas of injection molding and food should be regarded for machining the complex 3D surfaces.

In the future work, the milled components with complex 3D surfaces will be investigated and manufactured and its characteristics will be verifying the experimental outcomes.

\section{Data Availability}

The authors state that data used to support the findings of this study are included within the article.

\section{Conflicts of Interest}

The authors declare that there are no conflicts of interest regarding the publication of this article.

\section{Acknowledgments}

This work was supported by the project grant no T2020-12 funded by Ho Chi Minh City University of Technology and Education, Vietnam.

\section{References}

[1] J. A. Ghani, I. A. Choudhury, and H. H. Hassan, “Application of Taguchi method in the optimization of end milling parameters," Journal of Materials Processing Technology, vol. 145, no. 1, pp. 84-92, 2004.

[2] B. M. Gopalsamy, B. Mondal, and S. Ghosh, "“Taguchi method and ANOVA: an approach for process parameters optimization of hard machining while machining hardened steel," Journal of Scientific \& Industrial Research, vol. 68, no. August, pp. 686-695, 2009.

[3] G. . Samtaş, "Optimisation of cutting parameters during the face milling of AA5083-H111 with coated and uncoated inserts using Taguchi method," International Journal of $\mathrm{Ma}$ chining and Machinability of Materials, vol. 17, no. 3-4, pp. 211-232, 2015.

[4] H. Golpîra, H. Bevrani, and H. Golpîra, "Application of GA optimization for automatic generation control design in an interconnected power system," Energy Conversion and Management, vol. 52, no. 5, pp. 2247-2255, 2011.

[5] M. Soori, B. Arezoo, and M. Habibi, "Tool deflection error of three-axis computer numerical control milling machines, monitoring and minimizing by a virtual machining system," Journal of Manufacturing Science and Engineering, vol. 138, no. 8, pp. 1-11, 2016.

[6] M. K. Gupta, P. K. Sood, and V. S. Sharma, "Optimization of machining parameters and cutting fluids during nano-fluid based minimum quantity lubrication turning of titanium alloy by using evolutionary techniques," Journal of Cleaner Production, vol. 135, pp. 1276-1288, 2016.

[7] M. Basu and A. Chowdhury, "Cuckoo search algorithm for economic dispatch,” Energy, vol. 60, pp. 99-108, 2013.

[8] R. V. Rao and V. Patel, "Multiobjective optimization of heat exchangers using a modified teaching-learning-based optimization algorithm," Applied Mathematical Modelling, vol. 37, no. 3, pp. 1147-1162, 2013.

[9] R. V. Rao, V. J. Savsani, and D. P. Vakharia, "Teachinglearning-based optimization: a novel method for constrained mechanical design optimization problems," Computer-Aided Design, vol. 43, no. 3, pp. 303-315, 2011.
[10] R. V. Rao, V. J. Savsani, and D. P. Vakharia, "TeachingLearning-Based Optimization: an optimization method for continuous non-linear large scale problems," Information Sciences, vol. 183, no. 1, pp. 1-15, 2012.

[11] N. Le Chau, N. L. Ho, N. T. Tran, and T.-P. Dao, Analytical model and computing optimization of a compliant gripper for the assembly system of mini direct-current motor," International Journal of Ambient Computing and Intelligence, vol. 12, no. 1, pp. 1-28, 2021.

[12] R. V. Rao and R. B. Pawar, "Constrained design optimization of selected mechanical system components using Rao algorithms," Applied Soft Computing, vol. 89, Article ID 106141, 2020.

[13] K. Kadirgama, M. M. Noor, N. M. Zuki et al., "Optimization of surface roughness in end milling on mould aluminium alloys (AA6061-T6) using response surface method and radian basis function network," Jordan Journal of Mechanical and Industrial Engineering, vol. 2, no. 4, pp. 209-214, 2008.

[14] M. Safa, M. Ahmadi, J. Mehrmashadi et al., "Selection of the most influential parameters on vectorial crystal growth of highly oriented vertically aligned carbon nanotubes by adaptive neuro-fuzzy technique," International Journal of Hydromechatronics, vol. 3, no. 3, pp. 238-251, 2020.

[15] C. Zhu, W. Yan, X. Cai, S. Liu, T. H. Li, and G. Li, "Neural saliency algorithm guide bi-directional visual perception style transfer," CAAI Transactions on Intelligence Technology, vol. 5, no. 1, pp. 1-8, 2020.

[16] T. Sangeetha and G. M. Amalanathan, "Outlier detection in neutrosophic sets by using rough entropy based weighted density method," CAAI Transactions on Intelligence Technology, vol. 5, no. 2, pp. 121-127, 2020.

[17] M. Kaur, D. Singh, and V. Kumar, "Color image encryption using minimax differential evolution-based 7D hyper-chaotic map," Applied Physics B, vol. 126, no. 9, pp. 1-19, 2020.

[18] C. Kandilli and B. Mertoglu, "Optimisation design and operation parameters of a photovoltaic thermal system integrated with natural zeolite," International Journal of Hydromechatronics, vol. 3, no. 2, pp. 128-139, 2020.

[19] Z. Ali and T. Mahmood, "Complex neutrosophic generalised dice similarity measures and their application to decision making," CAAI Transactions on Intelligence Technology, vol. 5, no. 2, pp. 78-87, 2020.

[20] M. Kaur and D. Singh, "Multiobjective evolutionary optimization techniques based hyperchaotic map and their applications in image encryption," Multidimensional Systems and Signal Processing, vol. 32, no. 1, pp. 281-301, 2021.

[21] C. Prakash, H. K. Kansal, B. S. Pabla, and S. Puri, "Multiobjective optimization of powder mixed electric discharge machining parameters for fabrication of biocompatible layer on $\beta$-Ti alloy using NSGA-II coupled with Taguchi based response surface methodology," Journal of Mechanical Science and Technology, vol. 30, no. 9, pp. 4195-4204, 2016.

[22] S. Ghosh, P. Shivakumara, P. Roy, U. Pal, and T. Lu, "Graphology based handwritten character analysis for human behaviour identification," CAAI Transactions on Intelligence Technology, vol. 5, no. 1, pp. 55-65, 2020.

[23] H. S. Basavegowda, G. Dagnew, and G. Dagnew, "Deep learning approach for microarray cancer data classification," CAAI Transactions on Intelligence Technology, vol. 5, no. 1, pp. 22-33, 2020.

[24] B. Gupta, M. Tiwari, and S. Singh Lamba, "Visibility improvement and mass segmentation of mammogram images using quantile separated histogram equalisation with local 
contrast enhancement," CAAI Transactions on Intelligence Technology, vol. 4, no. 2, pp. 73-79, 2019.

[25] T. Wiens, "Engine speed reduction for hydraulic machinery using predictive algorithms," International Journal of Hydromechatronics, vol. 2, no. 1, pp. 16-31, 2019.

[26] M. Kaur and D. Singh, "Multi-modality medical image fusion technique using multiobjective differential evolution based deep neural networks," Journal of Ambient Intelligence and Humanized Computing, vol. 12, no. 2, pp. 2483-2493, 2021.

[27] T.-H. Hou, C.-H. Su, and W.-L. Liu, "Parameters optimization of a nano-particle wet milling process using the Taguchi method, response surface method and genetic algorithm," Powder Technology, vol. 173, no. 3, pp. 153-162, 2007.

[28] B. R. Murlidhar, R. K. Sinha, E. T. Mohamad, R. Sonkar, and M. Khorami, "The effects of particle swarm optimisation and genetic algorithm on ANN results in predicting pile bearing capacity," International Journal of Hydromechatronics, vol. 3 , no. 1, pp. 69-87, 2020.

[29] M. P. Dang, H. G. Le, N. L. Chau, and T.-P. Dao, "Optimization for a flexure hinge using an effective hybrid approach of fuzzy logic and moth-flame optimization algorithm," Mathematical Problems in Engineering, vol. 2021, Article ID 6622655, 18 pages, 2021.

[30] S. Chatterjee, S. Sarkar, S. Hore, N. Dey, A. S. Ashour, and V. E. Balas, "Particle swarm optimization trained neural network for structural failure prediction of multistoried RC buildings," Neural Computing and Applications, vol. 28, no. 8, pp. 2005-2016, 2017.

[31] H. Garg, "A hybrid PSO-GA algorithm for constrained optimization problems," Applied Mathematics and Computation, vol. 274, pp. 292-305, 2016.

[32] N. L. Chau, H. G. Le, T.-P. Dao, M. P. Dang, and V. A. Dang, "Efficient hybrid method of FEA-based RSM and PSO algorithm for multiobjective optimization design for a compliant rotary joint for upper limb assistive device," Mathematical Problems in Engineering, vol. 2019, pp. 1-14, Article ID 2587373, 2019.

[33] H. Garg, "A hybrid GSA-GA algorithm for constrained optimization problems," Information Sciences, vol. 478, pp. 499-523, 2019.

[34] H. Garg, "A hybrid GA-GSA algorithm for optimizing the performance of an industrial system by utilizing uncertain data," Handbook of Research on Artificial Intelligence Techniques Algorithms, vol. II, pp. 620-654, 2014.

[35] S.-C. Huang and T.-P. Dao, "Multiobjective optimal design of a 2-DOF flexure-based mechanism using hybrid approach of grey-taguchi coupled response surface methodology and entropy measurement," Arabian Journal for Science and Engineering, vol. 41, no. 12, pp. 5215-5231, 2016.

[36] N. Le Chau, N. T. Tran, and T.-P. Dao, "A multi-response optimal design of bistable compliant mechanism using efficient approach of desirability, fuzzy logic, ANFIS and LAPO algorithm," Applied Soft Computing, vol. 94, Article ID 106486, 2020.

[37] M. P. Dang, H. G. Le, N. Le Chau, and T.-P. Dao, "A multiobjective optimization design for a new linear compliant mechanism," Optimization and Engineering, vol. 21, no. 2, pp. $673-705,2020$

[38] Y. Shrivastava and B. Singh, "Assessment of stable cutting zone in CNC turning based on empirical mode decomposition and genetic algorithm approach," Proceedings of the Institution of Mechanical Engineers, Part C: Journal of Mechanical Engineering Science, vol. 232, no. 20, pp. 3573-3594, 2018.
[39] H. Eskandar, A. Sadollah, A. Bahreininejad, and M. Hamdi, "Water cycle algorithm - a novel metaheuristic optimization method for solving constrained engineering optimization problems," Computers \& Structures, vol. 110, pp. 151-166, 2012.

[40] A. Sadollah, H. Eskandar, and J. H. Kim, "Water cycle algorithm for solving constrained multiobjective optimization problems," Applied Soft Computing, vol. 27, pp. 279-298, 2015.

[41] A. Sadollah, H. Eskandar, A. Bahreininejad, and J. H. Kim, "Water cycle algorithm for solving multiobjective optimization problems," Soft Computing, vol. 19, no. 9, pp. 2587-2603, 2015.

[42] A. Sadollah, H. Eskandar, A. Bahreininejad, and J. H. Kim, "Water cycle algorithm with evaporation rate for solving constrained and unconstrained optimization problems," Applied Soft Computing, vol. 30, pp. 58-71, 2015.

[43] A. A. Heidari, R. Ali Abbaspour, and A. Rezaee Jordehi, "Gaussian bare-bones water cycle algorithm for optimal reactive power dispatch in electrical power systems," Applied Soft Computing, vol. 57, pp. 657-671, 2017.

[44] D. Kler, P. Sharma, A. Banerjee, K. P. S. Rana, and V. Kumar, "PV cell and module efficient parameters estimation using Evaporation Rate based Water Cycle Algorithm," Swarm and Evolutionary Computation, vol. 35, pp. 93-110, 2017.

[45] S. M. A. Pahnehkolaei, A. Alfi, A. Sadollah, and J. H. Kim, "Gradient-based water cycle algorithm with evaporation rate applied to chaos suppression," Applied Soft Computing, vol. 53, pp. 420-440, 2017.

[46] E. Osaba, J. D. Ser, A. Sadollah, M. N. Bilbao, and D. Camacho, "A discrete water cycle algorithm for solving the symmetric and asymmetric traveling salesman problem," Applied Soft Computing, vol. 71, pp. 277-290, 2018. 